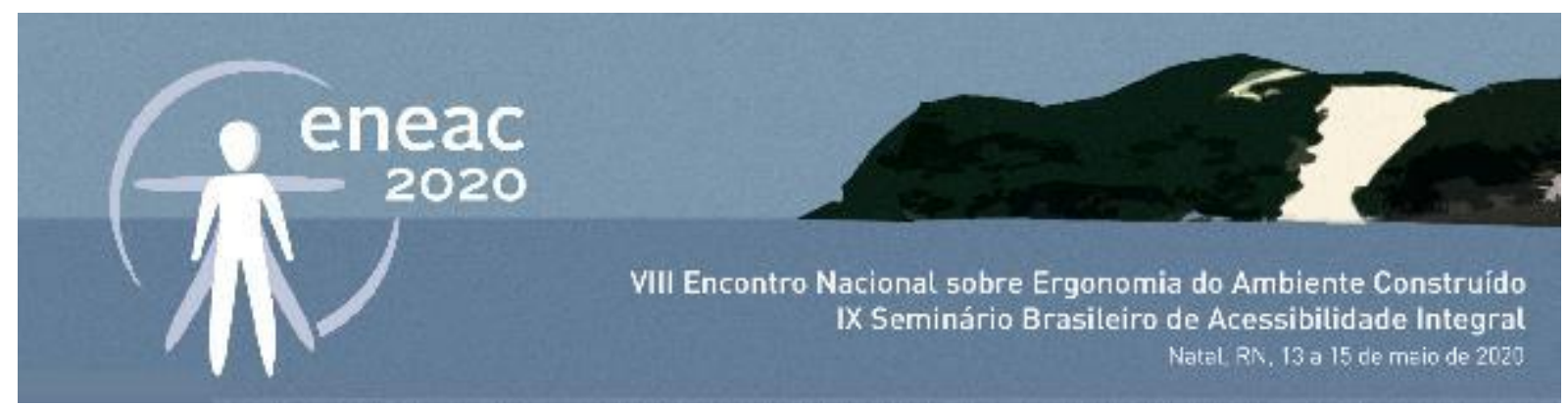

\title{
Turismo Acessível: Estudo de caso de hotel 3 estrelas em Fortaleza
}

\author{
Accessible Tourism: Case Study of 3 Star Hotel in Fortaleza
}

\author{
RENATA MELO ARAÚJO \\ Graduanda, Universidade Federal do Ceará, renatama_@arquitetura.ufc.br \\ HADRIEL LIMA DE BRITO \\ Graduando, Universidade Federal do Ceará, hadriellimah@gmail.com \\ CAMILLA NOGUEIRA SILVEIRA \\ Graduanda, Universidade Federal do Ceará, camillanoog@gmail.com
}

\section{RESUMO}

Este artigo é um recorte de uma pesquisa em andamento do Programa Institucional de Bolsas de Iniciação Científica (PIBIC), cujo objetivo é verificar a condição do setor hoteleiro, especificamente de Fortaleza, de receber turistas com deficiência e/ou mobilidade reduzida. Pretende-se com isso, contribuir com as políticas públicas na promoção de ações de melhoria da qualidade espacial para inclusão no setor de turismo na cidade de Fortaleza. Neste trabalho foi analisado um dos hotéis da orla principal da cidade para aplicação da Metodologia Avaliação Pós-Ocupação, proposta por Ornstein (1992), com desenvolvimento de relatório técnico seguindo um checklist, complementado com o registro fotográfico. Foram avaliados desde o entorno da edificação, as áreas comuns dessa até uma das unidades acessíveis, simulando o caminho que o hóspede faz para exercer suas atividades no hotel. Após levantados os pontos positivos e as inadequações, foram feitas recomendações no sentido de adequar as irregularidades encontradas considerando os sete princípios do Desenho Universal.

PALAVRAS-CHAVE: Acessibilidade; Desenho Universal; Turismo Acessível

\section{ABSTRACT}

This article is a cutout of an ongoing research of the Institutional Program of Scientific Initiation Scholarships (PIBIC), whose objective is to verify the condition of the hotel sector, specifically Fortaleza, to receive tourists with disabilities and/or reduced mobility. It is intended to contribute with the public policies in the promotion of actions to improve the spatial quality for inclusion in the tourism sector in the city of Fortaleza. In this work was analyzed one of the hotels of the main edge of the city to apply the Methodology Post-Occupation Evaluation, proposed by Ornstein (1992), with development of technical report following a checklist, complemented with photographic record. The common areas of the building were evaluated from the surroundings to one of the accessible units, 


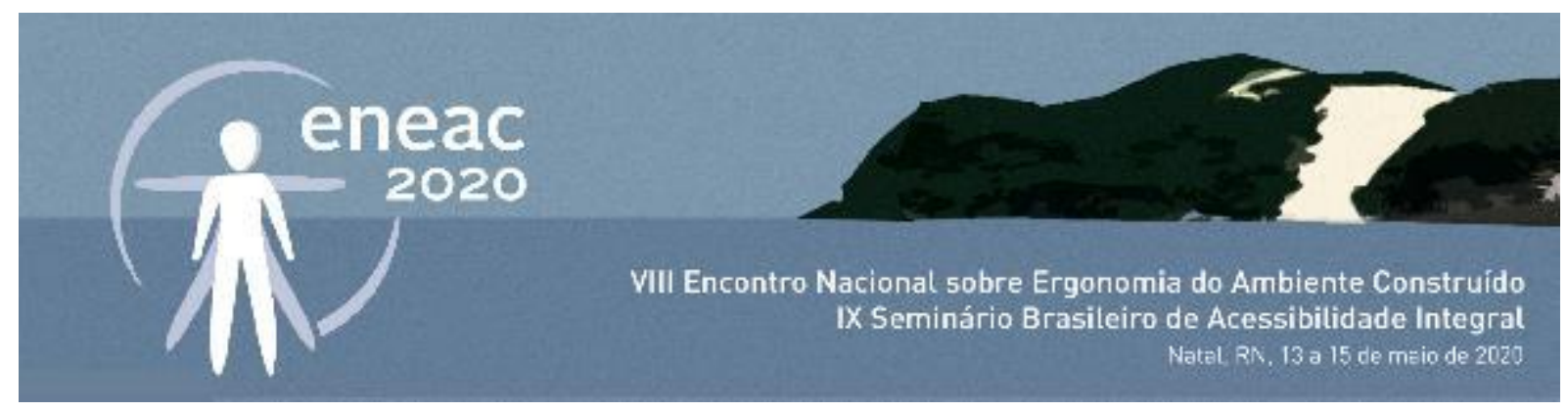

simulating the path that the guest takes to perform his activities in the hotel. After the positive points and inadequacies were raised, recommendations were made to adjust the irregularities found considering the seven principles of Universal Design.

KEYWORDS: Accessibility; Universal design; Affordable Tourism

\section{INTRODUÇÃO}

O presente trabalho tem como objetivo fazer uma avaliação, como estudo de caso, de um hotel consolidado em Fortaleza, que faz parte da paisagem da cidade há décadas, categorizado por três estrelas e que se intitula acessível a pessoas com mobilidade reduzida. Observando qual o nível de acessibilidade este oferece e o quão esse atende as normas e legislações vigentes.

A metodologia utilizada foi Avaliação Pós-Ocupação (Ornstein, 1992), com a visita in loco, registros fotográficos e aplicação de checklist. Esse último foi elaborado com base nas normativas da Associação Brasileira de Normas Técnicas (ABNT), NBR 9050/2015 e NBR NM 313, como também nas legislações específicas, Decreto no 5.296/2004 e Lei no 13.146/2015.

Este artigo é um recorte de uma pesquisa em curso do Programa Institucional de Bolsas de Iniciação Científica (PIBIC), intitulada "Acessibilidade arquitetônica x espaços de hospedagem: Fortaleza está preparada para receber pessoas com deficiência e/ou mobilidade reduzida?", com a colaboração dos alunos da disciplina de Desenho Universal do curso de Arquitetura e Urbanismo da Universidade Federal do Ceará (UFC).

\section{METODOLOGIA}

Como fundamentação teórica, buscou-se leitura de livros e artigos relacionados ao turismo acessível (SILVA et al, 2019; SANTIAGO, 2019), à temática de turismo e hotelaria (VARGAS \&PAIVA, 2016), bem como a pesquisa em fontes de dados oficiais, como o Ministério do Turismo e a Organização Mundial do Turismo (OMT) relacionados as condições de acessibilidade em hotéis no Brasil.

Para a elaboração da pesquisa de campo foi empregada a metodologia de Avaliação Pós-Ocupação (Ornstein, 1992). Segundo Villa, Saramago e Garcia (2016):

\footnotetext{
A APO pode ser caracterizada como conjunto de métodos e técnicas que incluem avaliações físicas de desempenho - formuladas em sistemas construtivos, conforto ambiental, funcionalidade, entre outros aspectos -, opiniões ou níveis de satisfação dos usuários e análises das relações ambiente construído versus comportamento humano.
}

Assim, são demonstrados os pontos positivos e as inadequações do ambiente construído, alimentando intervenções, melhorias e programas de manutenção e também realimentando diretrizes para futuros projetos (ROMÉRO \& ORNSTEIN, 2003 apud SCHÄFER \& GOMIDE 2014).

Em relação às ferramentas de pesquisa, foram empregados: i) vistorias técnicas com walkthrough e aplicação de checklist para aspectos construtivos e funcionais; ii) medições de condições ergonômicas; e iii) registros visuais. Foram consideradas as leis e normativas de acessibilidade definidas pelas normas da ABNT: NBR 9050/2015, que trata da acessibilidade nas edificações, mobiliário, espaços e equipamentos urbanos, e NBR NM 313, que normatiza a respeito dos 


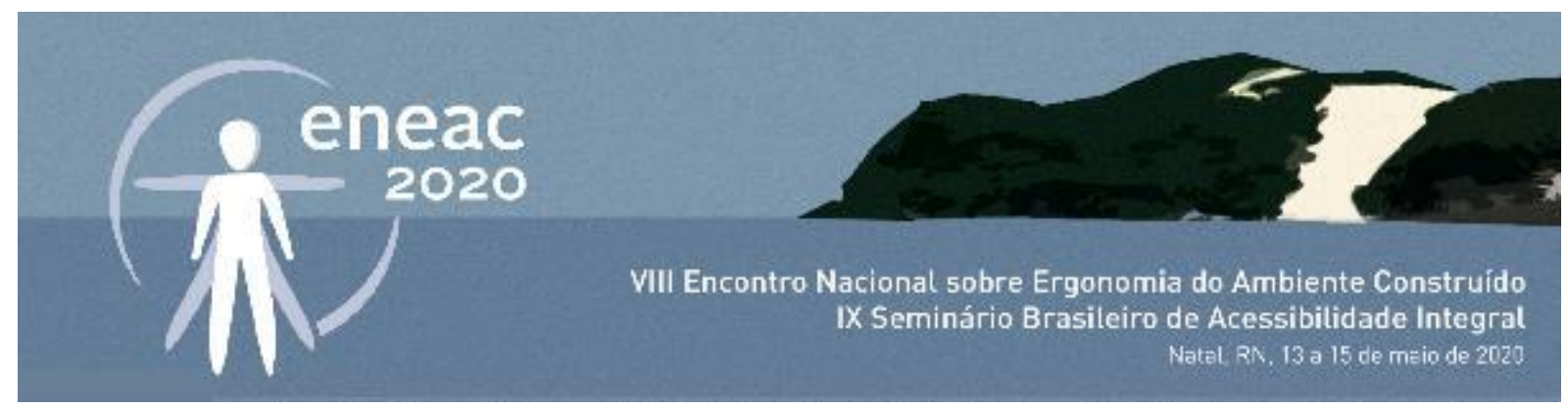

elevadores de passageiros e seus requisitos de segurança para construção e instalação particulares para a acessibilidade das pessoas. Também pelo Decreto $n$ o $5.296 / 2004$, que estabelece normas gerais e critérios básicos para a promoção da acessibilidade das pessoas com deficiência ou com mobilidade reduzida, e por último pela Lei no 13.146/2015, que institui a Lei Brasileira de Inclusão da Pessoa com Deficiência (Estatuto da Pessoa com Deficiência).

No checklist foram observados os seguintes critérios: i) meio urbano: travessias, passeios e vagas na via pública; ii) acessos: desníveis, obstáculos e estacionamento dentro do lote; iii) comunicação e sinalização: eficiência da sinalização voltada para deficientes auditivos e visuais, e sinalização de emergência; iv) mobiliário: dimensão dos assentos; v) circulações horizontais: desníveis, pavimentação e largura mínima de circulação; vi) circulações verticais: inclinação, largura mínima de circulação, inclinação transversal, corrimãos, guarda-corpo e sinalização de alerta; vii) portas: dimensão dos vãos, revestimento resistente a impacto e tipo de maçaneta; vii) sanitários: dimensão do sanitário (área de transferência e área de manobra), barras de apoio, altura dos equipamentos e tipos de torneira e válvula de descarga; e ix) usos específicos: faixa livre de circulação nos dormitórios acessíveis e demais áreas comuns (auditórios, piscina e restaurante).

\section{TURISMO ACESSÍVEL}

Com a urbanização do turismo, a produção do espaço é orientada para os visitantes, o fluxo e a permanência das pessoas são determinados pela sazonalidade, não só dos turistas, como também os habitantes, estes que também usufruem dos atrativos turísticos ou então estão empregados nas atividades da cadeia produtiva da atividade. (PAIVA, Ricardo. 2012)

Dentre dos vários setores representativos na atividade turística, os meios de hospedagem detém uma relação histórica muito importante frente ao desenvolvimento da atividade pelo mundo. Ainda mais, é correto afirmar que se trata de um amplo campo de promoção econômica, sociocultural e política da atividade turística.

Nessa atividade, as pessoas com mobilidade reduzida necessitam de adaptações até chegarem ao destino desejado e nele, para que possam circular pelos espaços urbanos e edificados com autonomia e segurança, princípios básicos da acessibilidade. A adequação dos serviços públicos é importante para os visitantes, também como para os que são visitados, caracterizando assim um ambiente de convívio em sociedade (FRANZEN, 2015). Diante disso, faz-se necessário que os pontos turísticos comecem a planejar as suas ações considerando que haja um posicionamento no mercado com um destino diferenciado, capaz de atrair os turistas de diversas partes do mundo, incluindo idosos, pessoas com mobilidade reduzida e com deficiência, atendendo assim a todos (RUSCHMANN, 1997).

Na visão de Darcy, Cameron e Pegg (2010) chama-se "turismo acessível" quando um destino turístico se utiliza do desenho universal para proporcionar acesso para todas as pessoas ao espaço urbano, aos produtos, aos serviços e aos equipamentos turísticos.

O Decreto no 5.296/2004, no artigo 8으, inciso IX, define desenho universal como:

Concepção de espaços, artefatos e produtos que visam atender simultaneamente todas as pessoas, com diferentes características antropométricas e sensoriais, de forma autônoma, segura e confortável, constituindo-se nos elementos ou soluções que compõem a acessibilidade. 


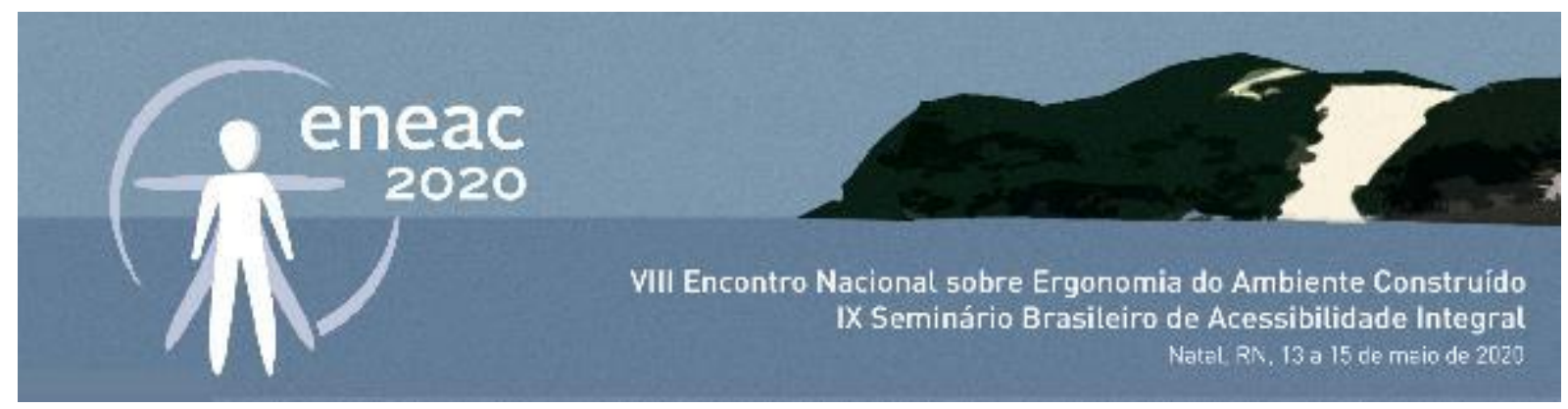

O Decreto ainda traz que a construção, reforma ou ampliação de edificações de uso público ou coletivo, como de natureza hoteleira, ou a mudança de destinação para estas edificações, deverá ser executada de modo que sejam ou se tornem acessíveis à pessoa com deficiência ou com mobilidade reduzida e devem atender aos princípios do desenho universal, tendo como referências básicas as normas técnicas de acessibilidade da ABNT, a legislação específica e as regras contidas no Decreto.

A norma 9050/2015 da ABNT também traz uma definição para desenho universal como um conceito de arquitetura e design centrados nas diversidades do ser humano. Portanto, as edificações, ambientes internos, urbanos e produtos devem atender a mais usuários, independentemente de suas características físicas, habilidades e faixa etária, favorecendo a biodiversidade humana e proporcionando uma melhor ergonomia para todos.

Foram adotados mundialmente sete princípios do Desenho Universal: i) uso equitativo, o espaço possa ser usado por diversas pessoas, independente de idade ou habilidade; ii) uso flexível, atenda a uma grande parte das preferências e habilidades das pessoas; iii) uso simples e intuitivo, possibilitar que seu uso seja de fácil compreensão, dispensando grandes habilidades de interpretação por parte das pessoas; iv) informação de fácil percepção, que seja legível as informações para pessoas com diferentes habilidades; v) tolerância ao erro, minimizar os riscos na utilização do ambiente; vi) baixo esforço físico, condições de ser usado de maneira eficiente e confortável; e vii) dimensão e espaço para aproximação e uso, dimensões confortáveis que independem da estatura do usuário.

O Decreto no 9.296/2018, artigo 1으, § 1으, determina que o atendimento aos princípios do desenho universal nos projetos arquitetônicos de hotéis, pousadas e estruturas similares pressupõe que $o$ estabelecimento, possa receber, na maior medida possível, o maior número de hóspedes, independentemente de sua condição física, sensorial, intelectual ou mental, e garantir que essas pessoas possam desfrutar de todas as comodidades oferecidas. Este determina que para os estabelecimentos já existentes, construídos até 29 de junho de 2004, atendam, no prazo máximo de quatro anos, as reformas necessárias para atendimento da lei.

Recentemente, O Estatuto da Pessoa com Deficiência - Lei Brasileira de Inclusão n. 13.146/2015, em seu Art. 8ㅇ, declara:
É dever do Estado, da sociedade e da família assegurar à pessoa com deficiência, com prioridade, a efetivação dos direitos referentes à vida, à saúde, à sexualidade, à paternidade e à maternidade, à alimentação, à habitação, à educação, à profissionalização, ao trabalho, à previdência social, à habilitação e à reabilitação, ao transporte, à acessibilidade, à cultura, ao desporto, ao turismo, ao lazer, à informação, à comunicação, aos avanços científicos e tecnológicos, à dignidade, ao respeito, à liberdade, à convivência familiar e comunitária, entre outros decorrentes da Constituição Federal, da Convenção sobre os Direitos das Pessoas com Deficiência e seu Protocolo Facultativo e das leis e de outras normas que garantam seu bem-estar pessoal, social e econômico.

Já no Art. 49. Define que "as empresas de transporte de fretamento e de turismo, na renovação de suas frotas, são obrigadas ao cumprimento do disposto nos art. 46 e 48 desta Lei".

\section{DISCUSSÃO E RESULTADOS DA ANÁLISE DE ACESSIBILIDADE}

O hotel analisado já faz parte da história de Fortaleza, sendo um dos primeiros a ser instalado na orla da cidade, na valorizada Avenida Beira Mar, próximo as principais atividades culturais e de comércio, voltadas principalmente para os turistas, como vemos na Figura 1. 


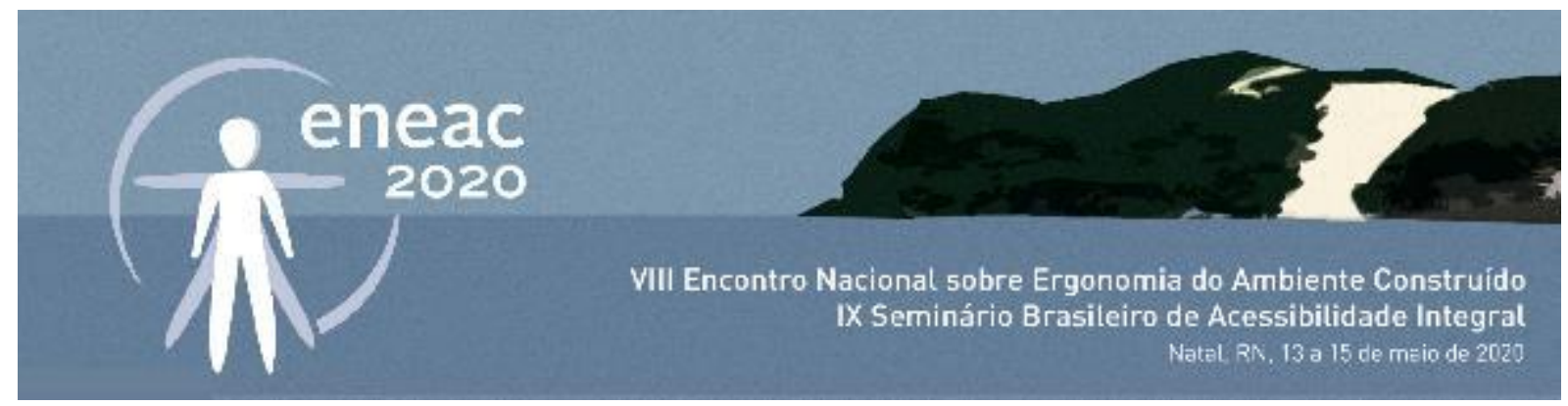

Figura 1: Localização do Hotel na orla de Fortaleza.

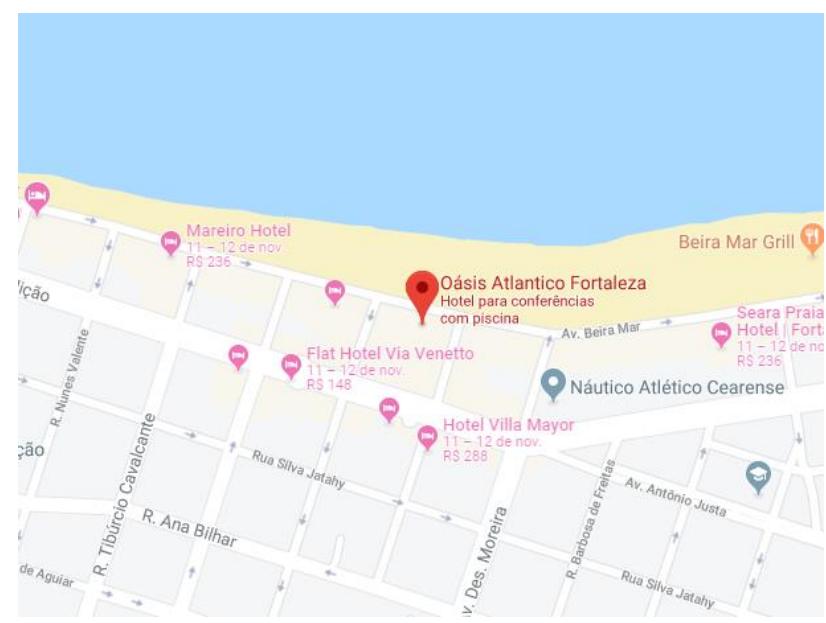

Fonte: Google Maps, 2019.

Sua classificação está subordinada ao Sistema Brasileiro de Classificação de Meios de Hospedagem (SBClass) que disponibiliza uma cartilha com os critérios mínimos de classificação das categorias de uma a cinco estrelas para os serviços de hospedagem categorizados com Hotel. A relação de certificação ainda não foram disponibilizados pelo portal do Ministério do Turismo (MTur), ao acessar o site há a informação de que não há meios de hospedagem com o certificado de classificação válido no âmbito do SBClass. Assim, recorreu-se aos sites de busca Trivago.com.br e Booking.com para obter uma classificação de mercado, que o classifica com 4 e 3 três estrelas respectivamente.

O site da Associação Brasileira de Indústria de Hotéis do Ceará (ABIH-CE) informa que um dos serviços do hotel é o Acesso a Pessoas com deficiência. O hotel dispõe de 269 acomodações, sendo apenas 4 unidades acessíveis, aquém da quantidade mínima de $10 \%$ dos quartos exigidos pela Lei $\mathrm{N}^{\circ}$ 13.146/15 para edificações já existentes, além de todas as unidades estarem dispostas no pavimento térreo da edificação, item que vai em desacordo a recomendação da NBR 9050/2015 de que as unidades devem estar distribuídas por todo o edifício.

Neste trabalho, a análise será dividida em seis pontos, partindo do entorno no qual se encontra a edificação, passando pelas áreas comuns, até a análise e levantamento de uma das unidades acessíveis. Em cada tópico, após a análise, algumas sugestões de melhorias são apontadas para adequar os ambientes às normas de acessibilidade.

\section{Meio urbano}

Faixas de pedestres sinalizadas se encontram a menos de 50 metros do acesso principal do hotel. Ao chegar pelo passeio do hotel, constatou-se a presença de faixa livre mínima de 1,2 metros ao decorrer de todo a fachada principal, sem obstáculos aéreos e com inclinação transversal inferior à $3 \%$, como pode-se ver na Figura 2. Apesar de o piso do passeio ser firme e regular, o mesmo é feito em pedra portuguesa, que o torna uma superfície trepidante que dificulta a locomoção de pessoas com mobilidade reduzida. 0 mesmo não possui piso tátil direcional em nenhum ponto, tornando o 


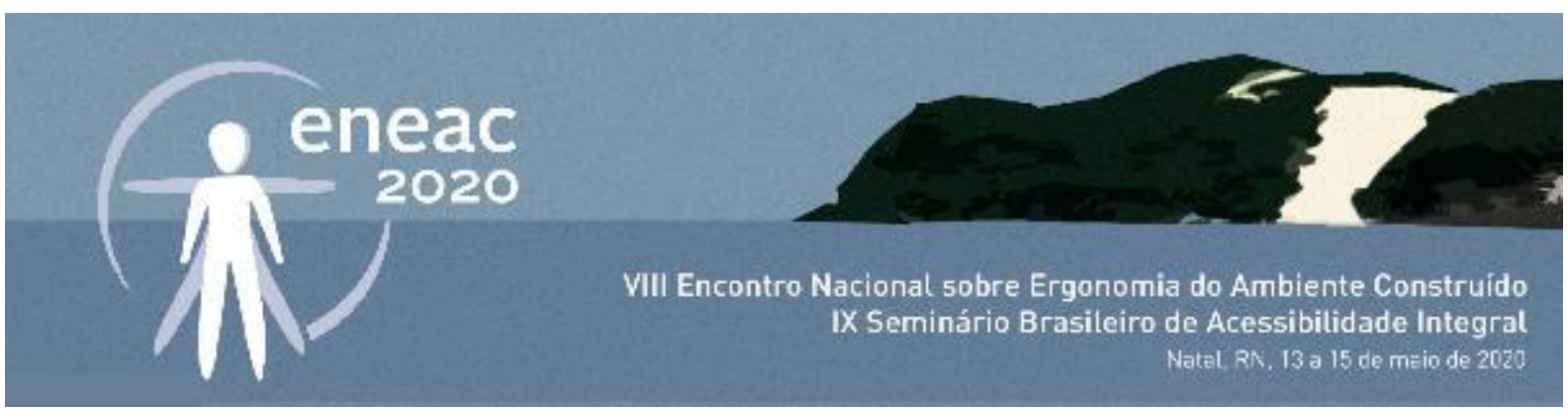

muro do hotel a única alternativa para deficientes visuais se guiarem.

Figura 2: Proximidade do acesso ao hotel. Passeio com faixa livre superior a 1,20m.

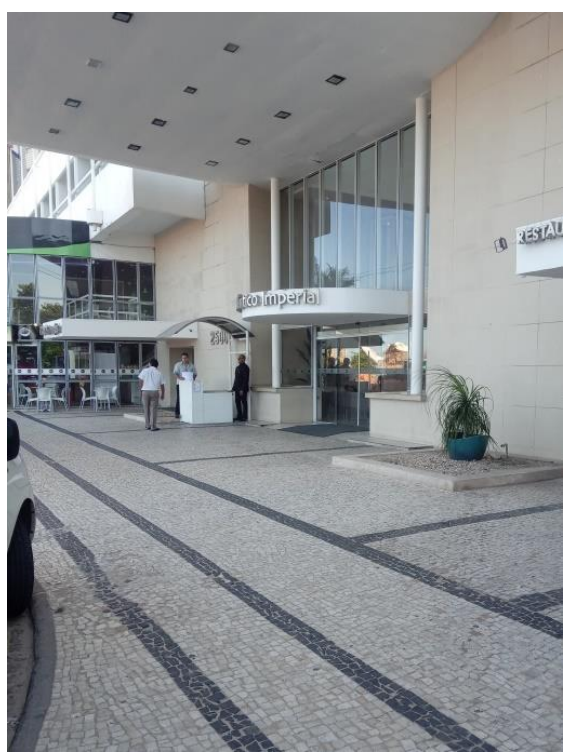

Fonte: Arquivo Pessoal.

Sugere-se implementar semáforos para pedestres com dispositivos que emitam sinais visuais e sonoros ou visuais e vibratórios sincronizados nos locais de travessia para torná-las mais seguras. Ainda, a substituição do revestimento do passeio por um piso não trepidante além da implantação de piso tátil direcional e de alerta.

\section{Acessos}

Os acessos externos do hotel se dividem em três: acesso principal, acesso ao Restaurante e acesso ao Centro de Convenções. Apenas o acesso principal é acessível, com uma rampa em inclinação adequada, pois nos demais se encontra um degrau impedindo a entrada universal aos espaços.

Apesar de o Restaurante e Centro de Eventos disporem de acesso interno pela recepção, recomendase implementar rampas nos acessos externos desses ambientes, democratizando o acesso dos mesmos pela área externa do hotel.

\section{Comunicação e sinalização/ Mobiliário}

Ao acessar pela entrada principal, não existe suporte informativo tátil, nem a presença de piso tátil direcional no hotel. De modo geral, notou-se a ausência de sinalização autoexplicativa na recepção e área de espera para as demais dependências.

Apesar de o balcão de atendimento encontrar-se em rota acessível, as dimensões e tipologia do mesmo não possibilitam o atendimento de pessoas em cadeiras de rodas. $\mathrm{O}$ mesmo possui altura de $1,11 \mathrm{~m}$, superior à recomendada na NBR 9050:2015, nem dispõe de profundidade livre em nenhuma seção do mesmo. O mobiliário encontrado está localizado fora da faixa livre de circulação, e possui 


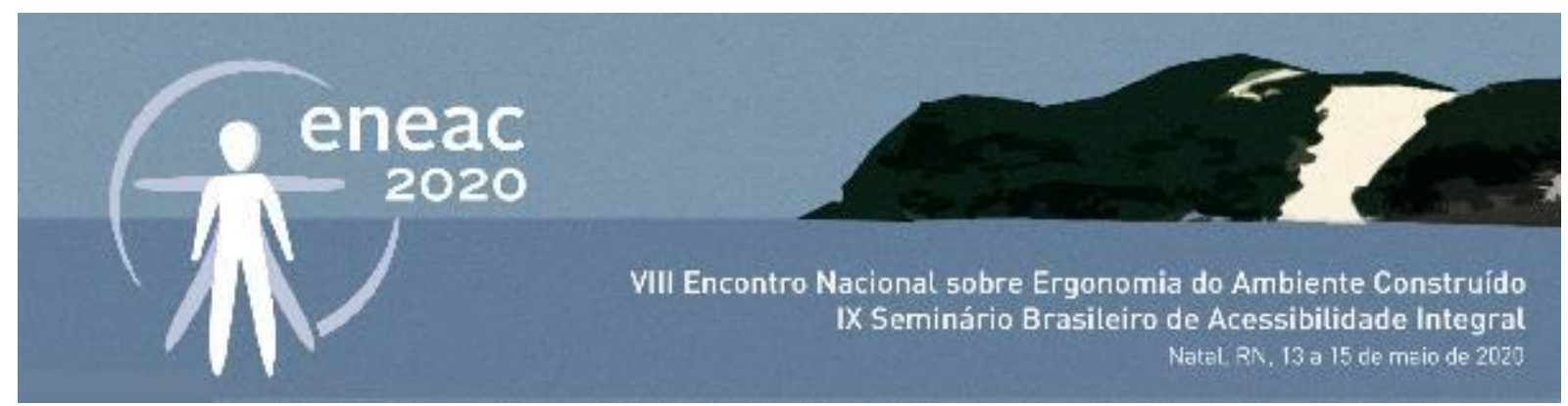

assentos de dimensões variadas.

Para melhorar o atendimento, sugere-se a implantação de piso tátil e direcional, bem como de mapa e sinalização tátil e visual para a formação de rota acessível. Além disso, a adaptação do balcão de atendimento conforme a norma já citada no parágrafo anterior, com altura entre 0,75 e 0,85 m do piso acabado, e profundidade livre de 0,30 m e altura livre mínima sob o tampo de 0,73 $\mathrm{m}$.

\section{Circulações horizontais e verticais}

Em todos os corredores de circulação do edifício, foi encontrada a largura mínima de 1,5 m, com pisos de superfícies regulares não trepidantes e antiderrapantes, com carpetes firmemente fixados. Nos quartos, não foram encontrados desnível no acesso aos mesmos e todos contam com abertura mínima de $0,8 \mathrm{~m}$, sempre com maçanetas do tipo alavanca, fixadas a 1,05 $\mathrm{m}$ do piso. Andando pela área comum, uma das portas de vidro não possuía faixa de sinalização. Recomenda-se a colocação de faixa de sinalização visual com espessura mínima de $50 \mathrm{~mm}$ em todas as portas de vidro.

Os elevadores atendem a todos os pavimentos do edifício, mas existe a disposição de algumas escadas que geralmente conectam dois pavimentos, além da escada de fuga, que atende a todos os pisos. Em todos os exemplares de escada foram encontradas dimensões adequadas de largura e altura dos degraus e patamar, todos com piso regular, firme e estável. Não foram encontradas sinalização nas bordas laterais, aplicada aos pisos e espelhos, em nenhuma destas escadas. Em algumas escadas há a falta de corrimão, e quando é encontrado, este não estão instalados em duas alturas, nem existe o prolongamento de $0,30 \mathrm{~m}$ no início ou fim das mesmas, como podemos ver a seguir na Figura 3. Em nenhuma escada foi encontrado piso tátil de alerta, prejudicando a circulação de pessoas com deficiências visuais.

Figura 3: Escada de acesso do pavimento térreo ao $1^{\circ}$ pavimento.

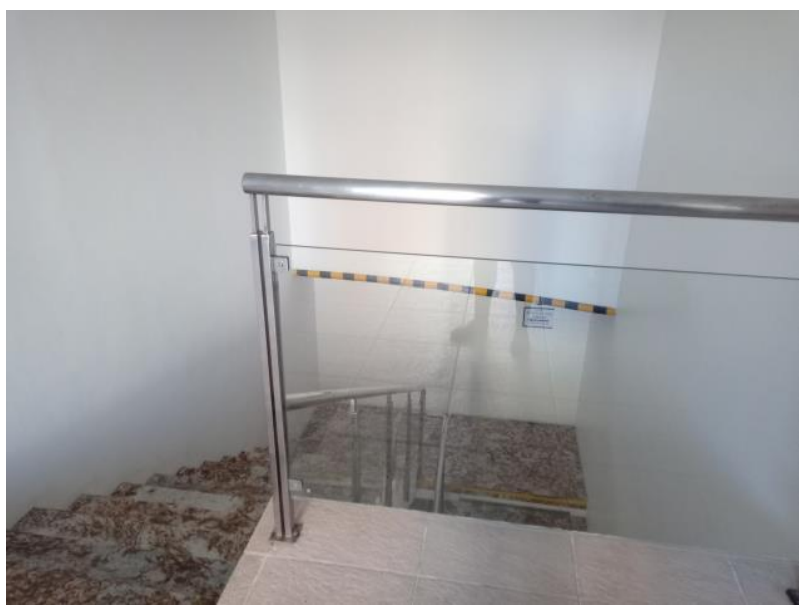

Fonte: Arquivo Pessoal.

As recomendações para a melhoria das escadas se iniciam com a aplicação de sinalização visual nas bordas dos degraus, aplicada nos pisos e espelhos, com no mínimo $3 \mathrm{~cm}$ de largura e $7 \mathrm{~cm}$ de comprimento. Com respeito aos corrimãos, recomenda-se a instalação de corrimãos com duas alturas, a 0,70 e 0,92 $\mathrm{m}$ do piso (medidas da face superior até o ponto central do piso do degrau), 


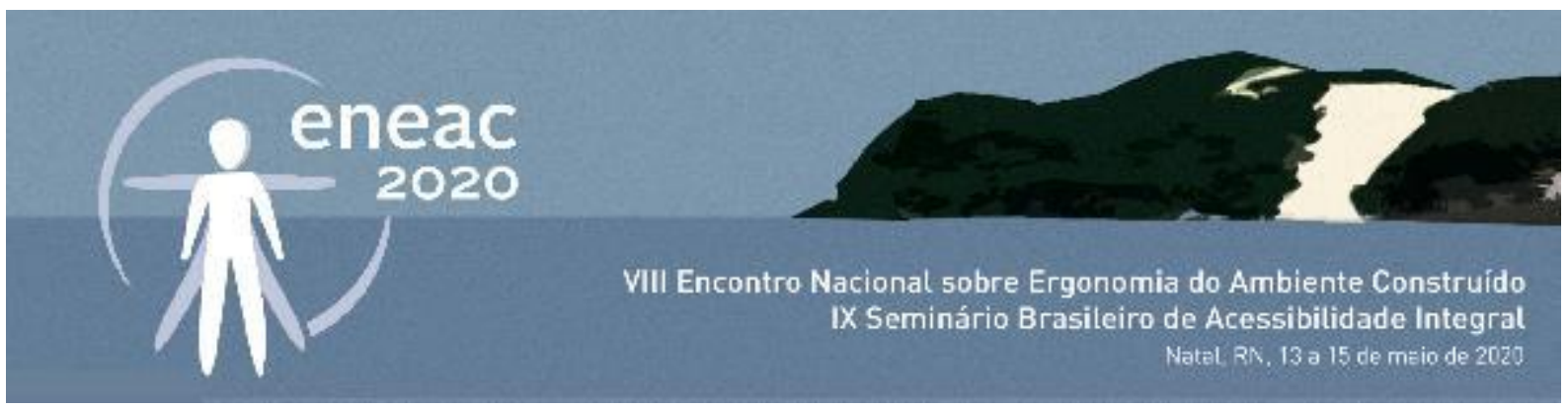

com seção circular de diâmetro entre 3 e 4,5 cm e com prolongamento de, no mínimo, 0,30 m antes do início e após o término da escada, com sinalização tátil identificando o pavimento, instalada na face superior do prolongamento. Piso tátil de alerta devem ser instalados no início e no término de cada escada.

Todos os elevadores do hotel se encontram agrupados em apenas um ponto do hotel, e possuem as mesmas dimensões, superiores a 1,1 por 1,40 m, e possuem comunicação em braile nos painéis de chamada e internos. O único problema constatado foi a altura do botão de chamada, que estava instalado com a altura de 1,35 do piso, portanto, a única sugestão de adequação é que ele esteja com a altura entre 0,90 e 1,1 m entre o piso acabado e a linha de centro do botão mais baixo e mais alto, respectivamente.

Existe apenas uma rampa em todo o hotel, como mostrado na Figura 4, e a mesma não está livre de alguns dos problemas encontrados nas demais circulações verticais, por exemplo, a ausência de corrimãos nos dois lados e não há piso tátil de alerta no início e fim. Apesar de ter largura superior a 1,2 m e piso regular, a rampa possui inclinação de $13,69 \%$, muito superior à recomendada na norma que rege esses equipamentos. Podemos concluir com as recomendações para melhorar a circulação da rampa: instalação de corrimão nos dois lados, com alturas de 0,70 e 0,92 m do piso (medidas da face superior até o ponto central do piso do patamar), de seção circular com diâmetro entre 3 e 4,5 $\mathrm{cm}$ e prolongamento de, no mínimo, 0,30 $\mathrm{m}$ antes do início e após o término da rampa; instalação de piso tátil de alerta no início e término da mesma.

Figura 4: Rampa de acesso no $1^{\circ}$ pavimento.

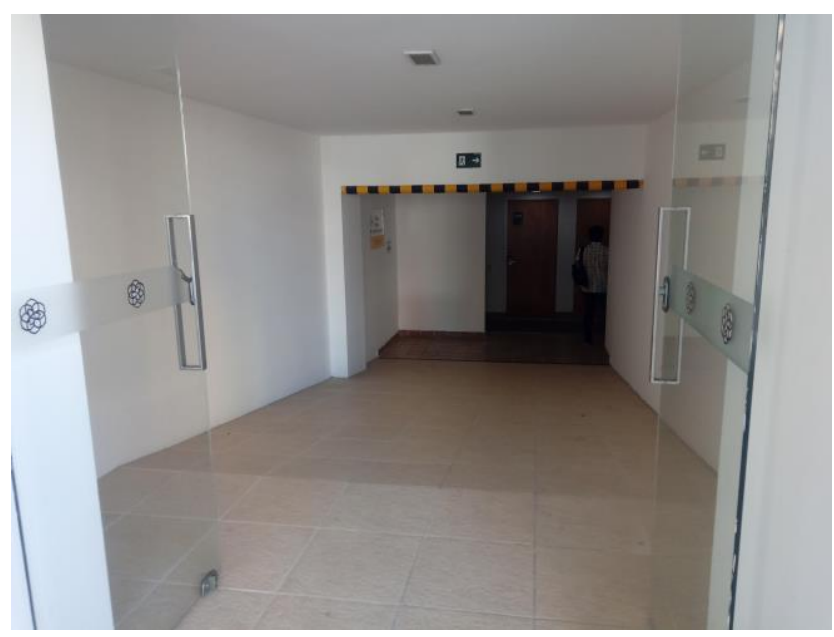

Fonte: Arquivo Pessoal.

\section{Sanitários Acessíveis das áreas comuns}

Em todos os pavimentos são encontrados sanitários acessíveis, um para cada sexo por pavimento, com entrada independente dos sanitários coletivos, e ambos se localizam em rotas acessíveis. 0 símbolo internacional de acesso está presente em todos os sanitários, e há também símbolos representativos de sanitários conforme a norma. A seguir, vemos na Figura 5 um dos sanitários 


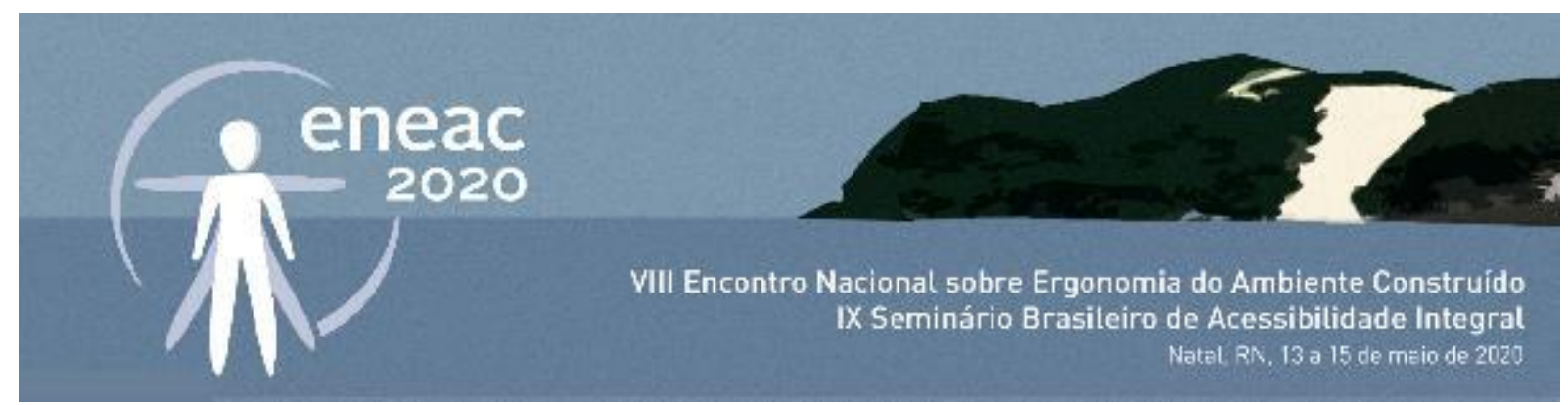

acessíveis do pavimento térreo.

Figura 5: Banheiro masculino acessível localizado no pavimento térreo.

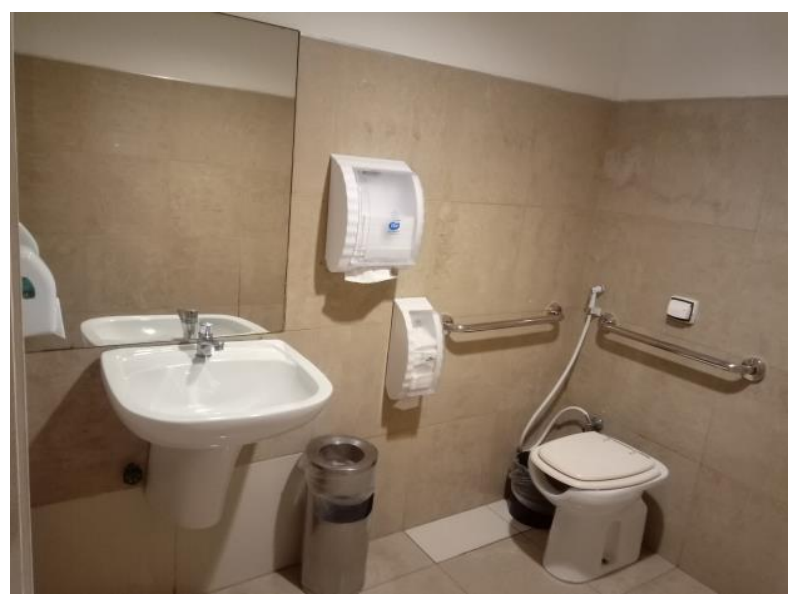

Fonte: Arquivo Pessoal.

As portas têm a largura superior a $0,80 \mathrm{~m}$ e possuem maçaneta do tipo alavanca, mas não possuem barra horizontal no lado interno. As dimensões dos ambientes superam as dimensões mínimas estabelecidas pela NBR 9050:2015 aqui já mencionada, e possuem área suficiente para transferência lateral à bacia sanitária. Não foram encontrados meios para sinalização de emergência em caso de acidentes ao lado da bacia e/ou do box. Em nem todos os exemplares existem contraste de cor entre piso, parede e teto, mas sempre o piso instalado não possui características antiderrapantes, se tornando bem escorregadio. As bacias sanitárias instaladas possuem abertura frontal, em desacordo com a norma, e as barras de apoios nas laterais da mesma possuem dimensões inferiores às estabelecidas e estão posicionadas mais altas do que deveriam, variando de acordo com cada sanitário. Apesar de os lavatórios serem de coluna suspensa, estes estão instalados com altura superior a $0,83 \mathrm{~m}$, e não há barras de apoio verticais.

Para melhor atender aos usuários, recomenda-se primeiramente a instalação das barras de apoio lateral e de fundo do sanitário com dimensões de no mínimo $0,8 \mathrm{~m}$, a $0,75 \mathrm{~m}$ do piso e a substituição por bacias sem abertura frontal. Recomenda-se também reduzir a altura dos lavatórios, bem como a instalação de barras verticais próximas aos lavatórios, a 0,9 $\mathrm{m}$ do piso e com comprimento mínimo de $0,4 \mathrm{~m}$. A instalação de barra horizontal na porta que funcione com a maçaneta também é necessária. A instalação de um piso antiderrapante é urgentemente necessária para evitar acidentes futuros.

\section{Quartos acessíveis}

Em visita a uma das unidades acessíveis, o contraste de cor entre piso e parede é percebido assim que adentramos no ambiente, como exemplificado na Figura 6 . Assim como todos os quartos do hotel, as portas têm largura superior a 0,8 m. A cama possui altura superior à recomendada, e recomenda-se a redução de modo a atender a norma. $O$ quarto dispõe de uma mesa com altura livre de $0,74 \mathrm{~m}$ que traz informações sobre o atendimento do hotel, mas não impressas também em braile. A movimentação dentro do quarto pode ser feita sem nenhum problema, e foi aferida uma 


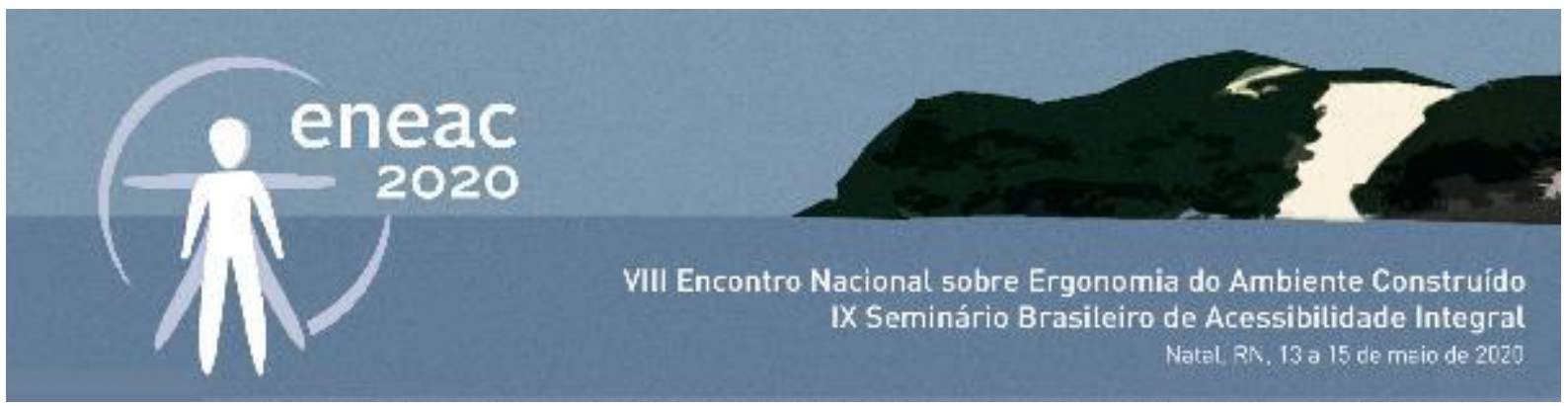

área de giro superior a 1,5 m.

Figura 6: Quarto acessível situado no pavimento térreo.

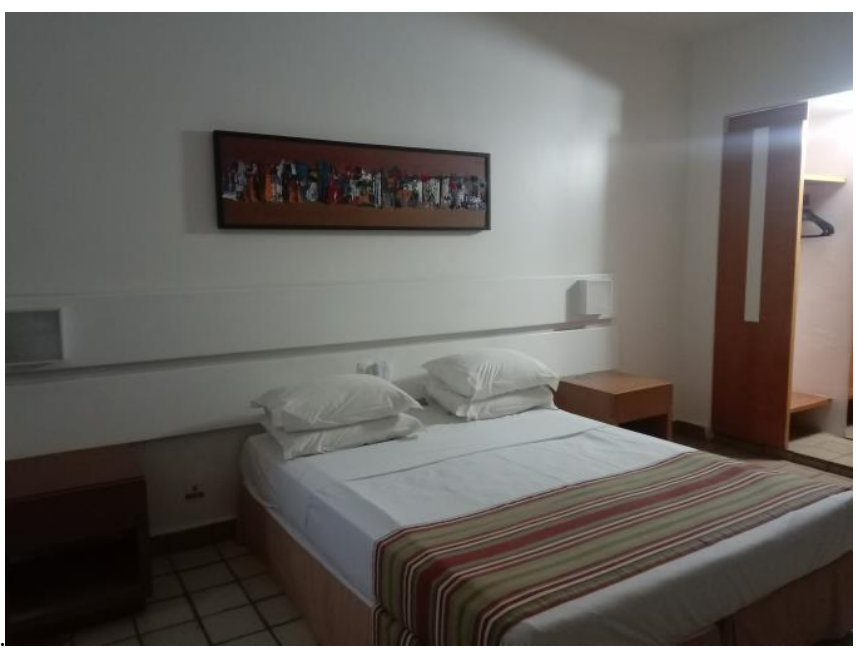

Fonte: Arquivo Pessoal.

O banheiro da unidade possui um desnível de $2 \mathrm{~cm}$, desnível também presente entre o nível do banheiro e do box. Todas as barras de apoio tinham dimensões inferiores às recomendadas e não estavam instaladas nos locais corretos, ainda, o lavatório não dispunha de nenhuma barra próxima. Assim como nos banheiros das áreas comuns, não há barra horizontal na porta. Recomenda-se uma reforma completa no ambiente devido a todos os problemas demonstrados anteriormente.

\section{CONSIDERAÇÕES FINAIS}

O hotel analisado foi projetado há quase cinco décadas, anterior as primeiras normativas de acessibilidades instituídas no país. Para adequação de novas funcionalidades e demandas, inclusive para atender as normas de acessibilidade, o hotel passou por algumas reformas e assim se intitulou como um hotel acessível, o que vai de encontro com os inúmeros problemas apontados pela análise no item anterior. Apesar de os usuários com deficiência conseguirem acessar o hotel e chegar até os quartos, inúmeros problemas foram encontrados, que assim comprometem a experiência de orientação, deslocamento e uso do hotel. Observa-se, no entanto, que o hotel tem potencial para tornar-se acessível, não necessitando de grandes reformas para tal, apenas adaptações e instalação de peças adequadas.

\section{REFERÊNCIAS}

ASSOCIAÇÃO BRASILEIRA DE NORMAS TÉCNICAS. NBR 9050: Acessibilidade e edificações, mobiliário espaços e equipamento urbanos. Rio de Janeiro, 2015.

ASSOCIAÇÃO BRASILEIRA DE NORMAS TÉCNICAS. NM 313: Elevadores de passageiros - Requisitos de segurança para construção e instalação - Requisitos particulares para a acessibilidade das pessoas, incluindo pessoas com deficiência. 


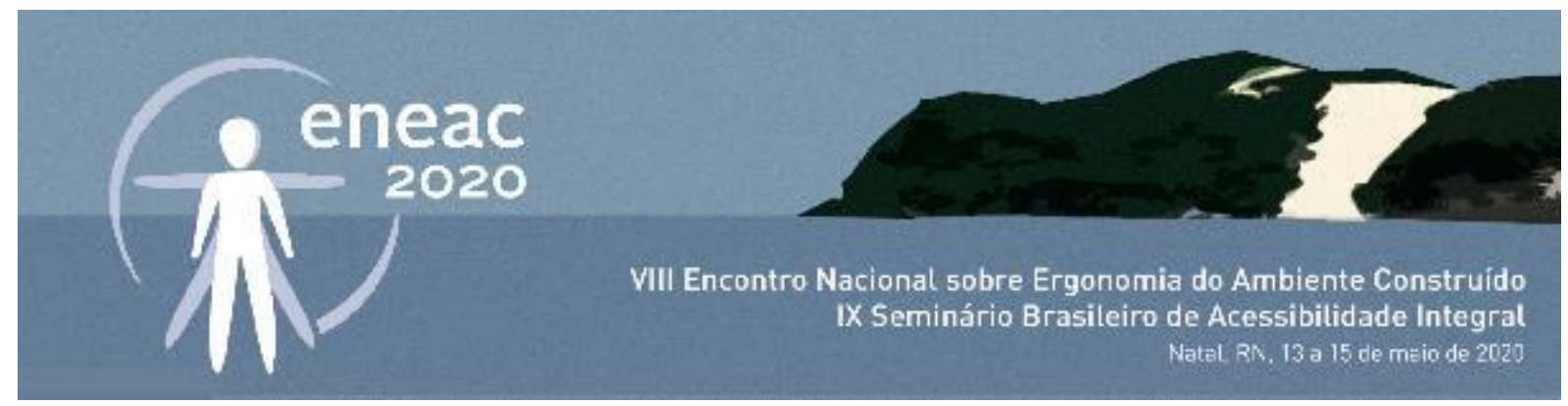

Rio de Janeiro, 2007.

BRASIL. Decreto no 5.296, de 2 de dezembro de 2004. Regulamenta as Leis nos 10.048, de 8 de novembro de 2000, que dá prioridade de atendimento às pessoas que especifica, e 10.098, de 19 de dezembro de 2000, que estabelece normas gerais e critérios básicos para a promoção da acessibilidade das pessoas portadoras de deficiência ou com mobilidade reduzida, e dá outras providências. Brasília, 2 de dezembro de 2004; 1830 da Independência e 116o da República.

BRASIL. Decreto no 9.296, de 1 de março de 2018. Regulamenta o art. 45 da Lei no 13.146, de 6 de julho de 2015 , que institui a Lei Brasileira de Inclusão da Pessoa com Deficiência - Estatuto da Pessoa com Deficiência. Brasília, 10 de março de 2018; 197 o da Independência e 130 da República.

BRASIL. Lei no 13.146, de 6 de julho de 2015. Institui a Lei Brasileira de Inclusão da Pessoa com Deficiência (Estatuto da Pessoa com Deficiência). Brasília, 6 de julho de 2015; 194ㅇ da Independência e 127으 da República.

BRITO, B. D. M. O turismo de resorts e o desenvolvimento do litoral sul da Paraíba. Dissertação (Mestrado em Desenvolvimento Regional). Universidade Estadual da Paraíba, Programa de Pós-Graduação e Pesquisa, 2011.

DARCY, S., CAMERON, B. \& PEGG, S. (2010). Accessible tourism and sustainability: a discussion and case study. In: Journal of Sustainable Tourism. Vol. 18, n. 4, p 515-537, 23p. Maio.

FRANZEN, L. I., OLIVEIRA, J. P. Acessibilidade em destinos turísticos: criação de pictogramas para mapeamento. 2015.

PAIVA, R. A dinâmica socioespacial do turismo na Região Metropolitana de Fortaleza; Teorias e práticas na Arquitetura e na Cidade Contemporâneas Complexidade, Mobilidade, Memória e Sustentabilidade. Natal, setembro de 2012.

SANTIAGO, Z. M. P.; ROCHA, C. B.; VILLAROUCO, V. Hospedagem acessivel: um novo quesito de qualidade na tipologia de hotéis. In: Colóquio Nacional sobre Cidades Litorâneas e Turismo - CILITUR II. Caderno de resumos [recurso eletrônico] / Comissão organizadora: Cristina Pereira de Araujo... [et al.]. - Recife: Ed. UFPE, 2019.

SILVA, S. C.; MORANO, R. P.; SANTIAGO, Z. M. P.; VILLAROUCO, V.; Hostel: uma forma de Hospitalidade Abert. p. 517-533 . In: Anais do 17을 Congresso Internacional de Ergonomia e Usabilidade de Interfaces Humano-Tecnologia e o 17 ㅇ Congresso Internacional de Ergonomia e Usabilidade de Interfaces e Interação Humano-Computador. São Paulo: Blucher, 2019. ISSN 2318-6968, DOI 10.5151/ergodesign2019-2.37

VARGAS, H. C.; PAIVA, R. A. (Org). Turismo, Arquitetura e Cidade. Barueri, SP: Manole, 2016.

VILLA, S. B.; SARAMAGO, R. de C. P.; GARCIA, L. C. Desenvolvimento de Metodologia de Avaliação Pós-ocupação do Programa Minha Casa Minha Vida: Aspectos Funcionais, Comportamentais e Ambientais. Texto para discussão / Instituto de Pesquisa Econômica Aplicada.- Brasília : Rio de Janeiro : Ipea, 2016. 